\title{
Maternal and child patient safety: a multiple criteria analysis of the decision- making preferences of nurse managers
}

\author{
Alexssandro da Silva 1 \\ Garibaldi Dantas Gurgel Júnior 2 \\ James Anthony Falk 3 \\ Marcel de Moraes Pedroso 4
}

\footnotetext{
1,2 Instituto Aggeu Magalhães. Fundação Oswaldo Cruz. Av. Professor Moraes Rego. s.n. Cidade Universitária. Campus UfPE. Recife, PE, Brasil. CEP: 50.670-420. E-mail: adm.alexssandro@gmail.com

3 Centro Universitário UniFBV, Wyden Brasil. Recife, PE, Brasil.

4 Instituto de Comunicação e Informação Científica e Tecnológica em Saúde. Fundação Oswaldo Cruz. Rio de Janeiro, RJ, Brasil.
}

\begin{abstract}
Objectives: to establish the decision preferences of nurse managers with emphasis on maternal-child patient safety, in order to understand how to prioritize actions and investments in the application of nursing assignments should be given.

Methods: a quantitative research with convenience sampling and a MCDA methodology (Multiple Criteria Decision Analysis) was operationalized by the PROMETHEE algorithm (Preference Ranking Organization Method for Enrichment Evaluations) through the use of a graphical preference capture tool and sensitivity analysis to ensure the robustness of the model. A consolidation of the criteria was carried out by means of the dimensions: reception, classification, assistance, orientation, team integration and administrative services, defined by criteria similarity and calculated by means of weighted preference indexes.

Results: a greater decision preference or relative importance was attributed to the professional category Obstetric Nurses (46.47\%), which stood out with the highest preferences in three dimensions: Integration (22.74\%), Assistance (13.37\%) and Administrative Aspects $(10.36 \%)$. The dimensions not directly involved with the patient (Team Integration and Administrative Aspects), altogether had a high decision-making preference or relative weight (47.96\%).

Conclusions: the model of decision-making preferences furnished innovative contributions in regard to the priority established on actions and investments to create greater safety for maternal and child patients.
\end{abstract}

Key words Decision making, Maternal and child health services, Patient safety 


\section{Introduction}

The occurrence of adverse health events in the hospital environment has been considered a major problem for patient safety worldwide, ${ }^{1}$ with serious and challenging consequences for public health. ${ }^{2}$ It is well known that there is a need to broaden the discussion in Brazil regarding events especially in maternal and child care, where there is a total dependency of the child patient under the care provided, without the capacity to express opinion or complaint, in order to adopt methods and systems that allow to deepen the scientific basis of the subject and define decision-making processes and decision-making models for patient safety.

Unintentional injury or damage resulting in temporary or permanent disability or impairment and / or prolongation of the length of stay in the institution or death as a consequence of the care provided to the patient by the care intervention is considered an adverse event (AE). ${ }^{3-4}$ The occurrence of harm or injury caused by the adverse event is related to care and not to the underlying disease, 1 and these occurrences are or should be preventable. 5 These events have a high incidence of avoidable occurrences, a large part associated to surgical procedures, medication errors or infections acquired in the hospital itself. 2 They are systemic in nature and are generated from the way hospital institutions are organized. For this reason, prevention requires attention focused on the causes and consequences of injuries, requiring an effort that goes beyond the identification of only guilty individuals. 6

Clinical practice factors that influence the occurrence of adverse events can be used to guide incident investigation. They serve to generate forms of risk assessment that focus on the analysis of causes and prevention of the occurrence of adverse events.? Systems, models and patient and staff analyzes should be absolute priorities in any risk and safety management strategy. ${ }^{8}$

The promotion of safer health interventions in hospitals, in order to avoid harm to the patient, has become a relevant public health issue, ${ }^{9}$ aiming at reducing morbidity and mortality, the time required for treatment of patients and, consequently, the reduction of care costs. 10

Studies exploring decision-making intelligence to define activities that have the greatest impact on patient safety should be priorities in health organizations, especially those focused on maternal and child care, as they deal with a physiological, programmable and continuous follow-up activity. Decisionmaking intelligence is understood here as "decision- making processes structured by a set of rules to decide that they incorporate the preferences of decision-makers and promote the capacity for adaptation and learning."11

Decision-making rationality differs from decision-making intelligence. Although some authors consider them equivalent - given that the rationality decision considers that individuals have complete information that maximizes their preferences - decision based on the concept of intelligence is a combination of several cognitive processes of diagnosis, adaptation to new situations for problem solution and learning, which have a context of incomplete and uncertain information. 11-13

There has been a growing number of studies that do not hide the drastic results regarding adverse health events, but not in the same proportion of studies that explore decision-making for safe care. This article proposes to contribute to this later aspect.

In this sense, the present study has as objective to elaborate the decision preferences of nurse managers with emphasis on the safety of the maternal-child patient, seeking to understand and subsidize decisions on how to prioritize actions and investments aimed at patient safety in the attributions of nursing.

\section{Methods}

It is a quantitative research, with sampling by convenience and with an approach based on the Multiple Criteria Decision Analysis (MCDA) methodology operationalized by the algorithm PROMETHEE Preference Ranking Organization Method for Enrichment Evaluations, through the use of a graphic capture tool of preferences and with sensitivity analysis to ensure the robustness of the model. 14

In this sense, this study was modeled through constructivist approaches (MDCA-C) 15,16 in four differentiated but intrinsically correlated decision support phases - (1) Identification of the context and decision makers, (2) Structuring the multicriteria model, (3) Analysis of results and (4) Decision support recommendations. 16

\section{$1^{\text {st }}$ Phase - Identification of the context and} decision makers

The institutional setting of the research was the hospitals certified as 'Child Friendly Hospital' in the city of Recife - Hospital das Clínicas, Agamenon Magalhães Hospital, Instituto de Medicina Integral 
Professor Fernando Figueira, Policlínica e Maternidade Arnaldo Marques, Maternidade Bandeira Filho, Unidade Mista Professor Barros Lima, Barão de Lucena Hospital and Centro Integrado de Saúde Amauri de Medeiros.

The Ministry of Health and the United Nations Children's Fund (UNICEF) have since 1992 certified, through the Baby-friendly Hospital Initiative (IHAC), public and private health institutions that meet the 'Ten Steps to Successful Breastfeeding ', the 'Friendly Woman Care' and a series of other requirements that seek adequate attention to the child and woman's health. ${ }^{17}$

The actors involved in the decision-making process are classified into three groups: decisionmakers, representatives and those acted upon. Decision-makers are those who have the institutional power to ratify a decision, who sets limits to the problem, specify the purpose to be achieved, and issue judgments. The power of decision is formally delegated to them. The representatives are the actors responsible for representing the decision-maker in the decision-making process; and those acted upon are those who passively suffer the consequences of the decisions taken, being able to intervene indirectly in the process by means of pressure on the decision makers and their representatives. 15,16

The eight nursing coordinators of certified maternity hospitals were included as research subjects. These subjects were the target population of the research and each one was identified, in this study, as a 'decision-maker' actor, the only one to answer in the data collection. The representatives technicians / auxiliaries, nurses and obstetrician nurses - and those acted upon - patients and companions - were identified only to contextualize the decision-making process, but did not respond in the data collection.

\section{2nd Phase - Structuring of the multicriteria model}

In this phase, an evaluation model was defined for PROMETHEE's ranking of decision preferences. Criteria were considered as the attributions of the nursing professionals involved in the reception and classification of risk in obstetrics, included the criteria mentioned in the Handbook of Reception and Risk Classification in Obstetrics of the Stork Network of the Ministry of Health. 18 A total of 25 criteria (TA1, TA2 , .., E1, E2, .., EO4) grouped into three professional nursing categories: TANursing Technicians and Assistants; E - Nurses and EO - Obstetric Nurses, as listed in Table 1.
The Manual of Reception and Risk Classification in Obstetrics / A\&CR, the basic instrument of this study, is an initiative of the Ministry of Health, from the Stork Network, which, since 2011, aims to provide better health care and quality for women and children. This Manual of support to the maternity and obstetrical services in Brazil is an instrument designed to favor the organization of the reception of the patients at the entrance doors of obstetric emergency services, guaranteeing quality access to women in the puerperal pregnancy period. The instrument was elaborated from the maternity experiences that have been implemented by A\&CR and includes the Risk Classification Protocol, which is a tool for clinical support decision. ${ }^{18}$

The ranking of preferences is the ordering of these criteria - attributions of nursing professionals contained in the A\&CR Manual that were based on their importance for patient safety. The indexes that enabled the ranking of decision preferences were captured through a digital questionnaire - a data collection instrument, modeled with the 25 nursing criteria, and answered by each nursing decision maker through the preferences capture tool.

To define the weight to each criterion in the paired graph, the decision maker used the D-Sight Software, which generated three paired combinations between the three professional categories Nursing Technicians and Assiatants (TA); Nurses (E); and Obstetric Nurses (EO) - from which 108 matched combinations among the 25 criteria were found, of which 36 were among the 9 criteria of the Nursing Technicians and Assiatants, 66 pairings between the 12 criteria of the Nurses and 6 combinations among the 4 criteria of the Obstetric Nurses, as presented in the Figure 1.

D-Sight is a flexible software that can be tailored to meet the needs of organizations of different types, using a structured approach for evaluation or decision-making projects. It operates in web interface with the PROMETHEE algorithm - Preference Ranking Organization Method for Enrichment Evaluations, which is a prescriptive method that allows to classify the actions according to the preferences of the decision makers. 14

The preference value $P_{j}\left(a_{i}, a_{l}\right)$ is a function of the difference $f_{j}\left(a_{i}\right)-f_{j}\left(a_{\nu}\right)$ and corresponds to the degree of preference that the decision maker expressed $a_{i}$ compared to criterion $a_{l}$. The evaluations of two criteria $a_{i}$ and $a_{l}$ are a number between 0 and 1 , where $P_{j}=0$ does not correspond to any preference, while $P_{j}=1$ corresponds to a total preference. The weighted average of the preferences for obtaining the indices of each criterion is calculated by the 
Table 1

Criteria with attributions of nursing professionals.

\begin{tabular}{|c|c|c|c|}
\hline $\begin{array}{l}\text { Professional } \\
\text { Categories }\end{array}$ & Order & Code & CritCriteria (Nursing Assignments) \\
\hline Nursing & 1 & TA1 & Accept the woman and companion in a cordial and responsible manner. \\
\hline Technicians and & 2 & TA2 & Listen to the woman's complaint, fears and expectations. \\
\hline \multirow[t]{7}{*}{ Assistants (TA) } & 3 & TA3 & $\begin{array}{l}\text { Accommodate and / or position the user appropriately so that it can be assessed in } \\
\text { the risk classification. }\end{array}$ \\
\hline & 4 & TA4 & Gauge the woman's vital signs. \\
\hline & 5 & TA5 & Refer the client for care after risk classification. \\
\hline & 6 & TA6 & $\begin{array}{l}\text { Forward / orient user regarding the location of the examination and medication, } \\
\text { when applicable. }\end{array}$ \\
\hline & 7 & TA7 & Be alert to the woman's reclassification needs while awaiting care. \\
\hline & & TA8 & Refer users to Social Work and Psychology when appropriate. \\
\hline & $\begin{array}{l}8 \\
9\end{array}$ & TA9 & $\begin{array}{l}\text { Making the shift on a regular basis is not allowed to leave the shift without another } \\
\text { employee taking it. }\end{array}$ \\
\hline
\end{tabular}

Nurses (E)

Obstetric Nurses
Receive the information sheets, evaluating the women's priority in an agile and responsible manner, according to the complaint presented.

Call the woman by name, also requesting the presence of a companion.

Classify the risk quickly and efficiently, following the protocol adopted.

Attach the "notice of violence" form when there is suspicion or confirmation of the case.

Record classification data in the answer sheet, signaling the woman's classification by color.

Record rankings on the A \& CR map.

Orient the woman in a clear way about her situation and the waiting time of the service.

Provide the technician's answer sheet to be placed in the offices.

Reclassify users when necessary.

Be integrated with the multiprofessional team of the obstetrical / maternity center, seeking a better solution to the problems of the user.

Supervise the work of the technician / nursing assistant and trainee, guiding correctly when necessary.

Record the occurrences of the sector in the proper book.

Source: Elaborated by the authors of the research based on the Manual of Reception and Risk Classification in Obstetrics - Rede Cegonha 2014. 


\section{Structure for Graphical Capture and Stability Intervals - Software D-Sight}

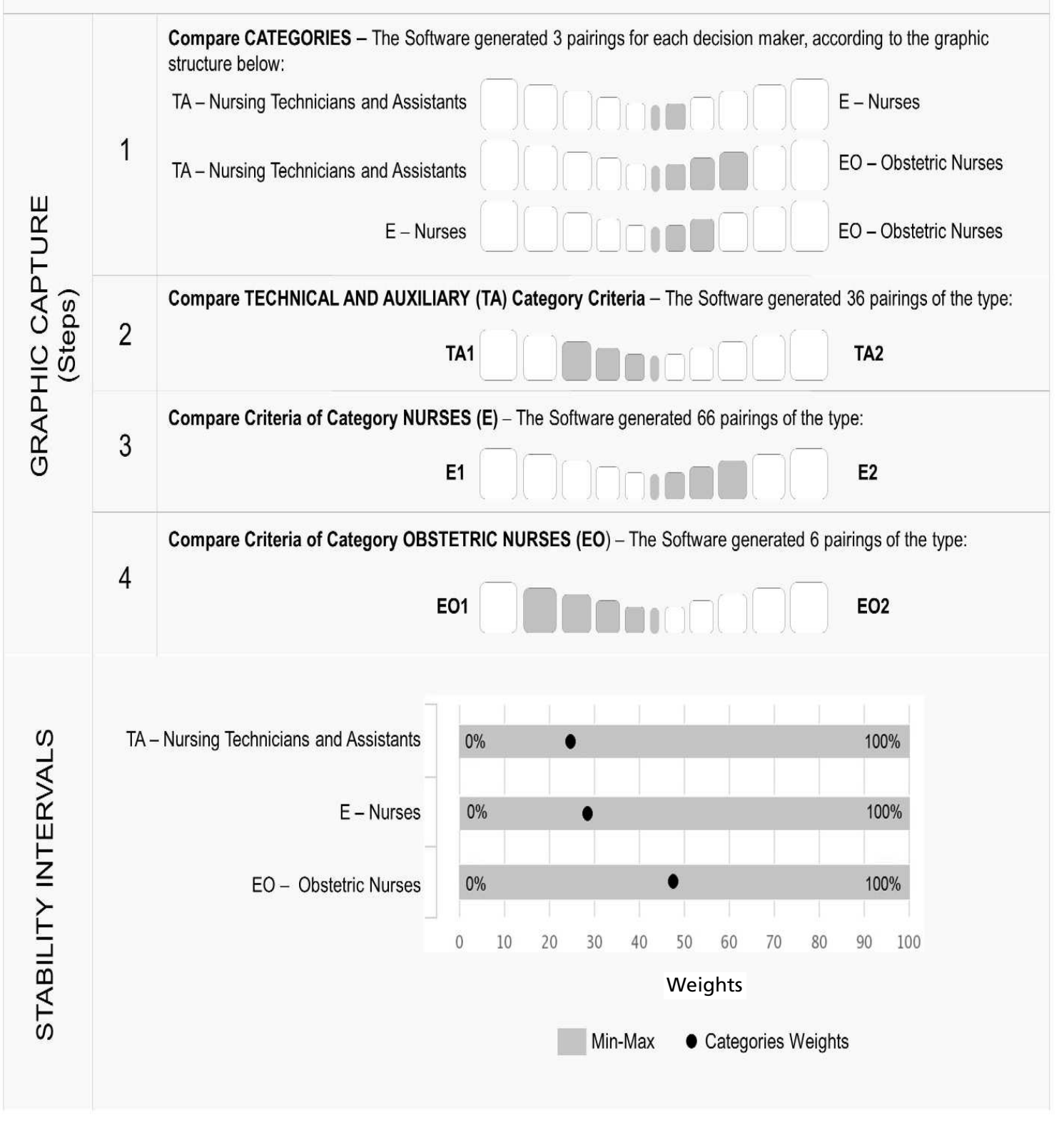

Source: Prepared by research authors based on D-Sight Software. 
Figure 2

Actor tree, criteria and dimensions.

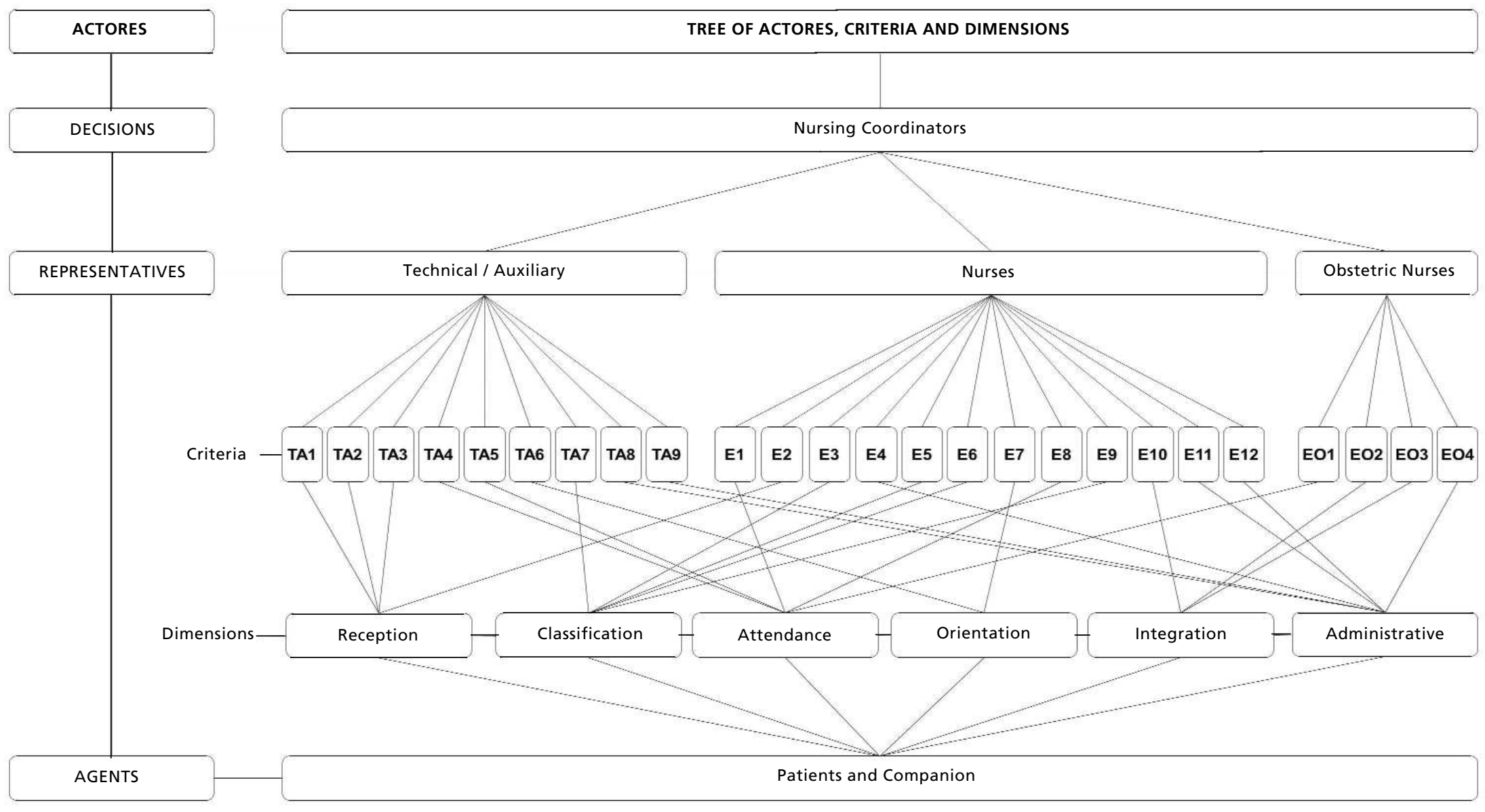

Source: Prepared by the authors of the research. 
formula: 14

$k$

where:

$\begin{array}{ll}\sum_{w_{j}} P_{j}=\left(a_{i}, a_{l}\right) \quad & k=\text { Number of Criteria } \\ & j=\text { Criteria } \\ & P=\text { Preference } \\ j & \end{array}$

To classify in dimensions, simultaneously to the professional categorization - TA, E and EO - the chosen criteria for the ranking were also categorized according to the purpose of each assignment of the nursing professionals. It was classified in six different dimensions with criteria grouped by similarity - Reception, Classification, Attendance, Orientation, Team Integration and Administrative Aspects - with preferences indexes calculated by weighing the results obtained in the use of the Software graphic capture tool D-Sight.

For data analysis, these six dimensions formed a decision model of systematized structure and divided into smaller parts - criteria, given their complexity; and then re-integrated into dimensions to form a consolidated analysis that best represented the synthesis of decision-making preferences. In this sense, Figure 2 illustrates a tree-shaped scheme in which the relations between the actors, the criteria and their integration are presented to the dimensions that consolidate the synthesis of decision preferences.

Sensitivity analysis using the D-Sight Software assures us that, in the evaluation of the criteria by the decision makers, the input values of the model are in line with the final result within the stability range (Figure 1), there being no incoherence of preferences type $\mathrm{A}<\mathrm{C}$ in the application of $\operatorname{logic} \mathrm{A}>\mathrm{B}>\mathrm{C}$ (strict preference). As for the index values of each dimension, there was no direct participation of the decision makers, since they were calculated by summing the criteria related to each dimension, weighted by the respective Professional Category Weights $(w C P)$, according to the relationships proposed in Figure 2 and summarized in the following formula:

$\begin{array}{ll}k & \text { where: } \\ \Sigma_{j} w C P_{j} & \begin{array}{l}k=\text { Number of Decision makers } \\ j=\text { Category Criteria } \\ \end{array} \\ j=1 & \begin{array}{l}C P=\text { Professional Category Index } \\ \text { Ceight of Professional Category } \\ \text { Criteria }\end{array}\end{array}$

3nd Phase - Analysis of results

For the result of the preferences by criterion, the graphic pairing formula proposed in the 2 nd Phase Structuring of the multicriteria model was applied, by means of the preference differences function associated with each criterion, selecting in the graphic capture by the decision maker.

\section{$4^{\text {nd }}$ Phase - Decision support recommendations}

The decision-making process is permeated by two paradigms. On the one hand, the rationalist paradigm with the basic objective of finding the optimal solution, without taking into account the subjectivity of the actors; and on the other hand, the constructivist whose objective is the generation of knowledge for the decision makers. The constructivist approach simultaneously considers elements of an objective and subjective nature, and privileges the participation and learning of decision makers as pillars of the paradigm. 16

In this study, we sought to construct a recommendable model, not necessarily optimal, but that took into account the heterogeneity and types of knowledge of the actors involved and that applied its subjectivity importance, choosing to create a constructivist decision-making model.

The present study is in accordance with Resolution 466/12 of the National Health Council (CNS), with the participation of the research subjects conditioned to the signing of the Informed Consent Term (TCLE). It is a cut of the macroproject: Integrated and sustainable care networks: theory, practice and possibilities of innovation in the interinstitutional dynamics of SUS regulation (REG-SUS), approved by the Research Ethics Committee of Aggeu Magalhães Institute/FIOCRUZ-PE under the number CAAE 50906915.0.0000.5190 / 2016 CONEP.

\section{Results}

For a better understanding of how the graphic matching formula was applied, based on criterion E10 - 'Being integrated with the obstetrical / maternity center multiprofessional team, seeking a better resolution of the user's problems, the preference index of 11.34 of this criterion was obtained from the graphical selection result of each pair of criteria, where the CE1 decision maker selected the most important ones on a scale with a difference of 0.2 $(0.2,0.4,0.6,0.8 ; 1.0)$, being 0.0 for non-preference and 1.0 for a total preference, applying the formula: 


$$
\begin{aligned}
& \sum_{w_{j}} P_{j} \\
& j=1
\end{aligned}
$$

We have:

$$
\begin{aligned}
& 12 \text { where: } \\
& \sum_{w_{10}} P_{10}=11.34 \quad k=\text { Number of Nurses' Criteria } \\
& (\mathrm{E}=12) \\
& j=\text { Criteria } \\
& j=10 \quad P=\text { Preference E10 } \\
& W=\text { Weight }
\end{aligned}
$$

In the same logic of application of criterion E10, the preference indexes of all other criteria were consolidated, resulting in the table of preference indexes (Table 2), which presents the result of all the decision-makers, grouped by professional category and consolidated with mean and standard deviation provided.

By weighing the indices of the criteria in Table 2 with their respective professional categories, it was possible to calculate the preference indices of the six dimensions shown in Figure 2. This result was obtained by applying the following formula:

$k$

$$
\begin{array}{ll}
\sum_{j} w C P_{j} & \begin{array}{l}
k=\text { Number of Decision makers } \\
j=\text { Category Criteria } \\
C P=
\end{array} \\
j=1 & \text { Index } \\
& W=\text { Weight of Professional } \\
& \text { Category Criteria }
\end{array}
$$

To obtain Criterion EO1 (36.80\%) - 'Assist the women who are assigned to them, in a welcoming way, according to institutional protocol and with the immediate access to the obstetrician, when necessary' - belonging to Professional Category EO (55.00\%) of Decision CE8, which had the highest preference among all the criteria of the dimensions (20.24\%) and was grouped by similarity to the Dimension Attendance (23.30\%), the following calculation was used:

$K=8$

$x \sum E O 1 . w E O_{C E 8}$

$j=E O 1$ de $C E 8$
We have:

$K=8$

$x \sum 36.80 \times 0.55_{C E 8}=20.24$

$j=E O 1$ de $C E 8$

where:

$k=$ Number of Decision makers $=8$

$j=$ Category Criterion $=\mathrm{EO} 1$ do $\mathrm{CE} 8=$ $36.80 \%$

$C P=$ Professional Category Index $=\mathrm{EO}=$ $55.00 \%$

$W=$ Weight of Professional Category Criteria $=55.00 / 100=0.55$

$x \sum\left(\mathrm{EOI}_{C E}+\mathrm{EOI}_{\mathrm{CE2} 2}+\mathrm{EOI}_{\mathrm{CE} 3}+\mathrm{EOI}_{\mathrm{CE4}}+\mathrm{EOI}_{\mathrm{CES}}\right.$ $\left.+E O 1_{C E 6}+E O 1_{C E 7}+20,24_{C E 8}\right) / 8$

$x \sum(19.62+9.47+13.57+10.60+12.38+9.99+$ $11.10+20.24) / 8$

$x \Sigma=E O 1=106.97 / 8=13.37$

With the calculations proposed in the method being applied to all the criteria, with all the decision makers, it was possible to standardize Table 3 which shows all the values of the already weighted criteria and grouped by dimension. In this table, it may be observed that most decision makers (25.89\%) preferred the criteria that optimize 'team integration'; followed by criteria for maternal and child 'attendance ' $(23.30 \%)$.

Based on the criteria, EO3 - 'Being integrated with the multiprofessional team of the obstetrical / maternity center, seeking a better solution to the women' s problems $(12.83 \%)$ - collaborated $49,55 \%$ with the index of dimension 'Team Integration' (25.89\%), being exceeded only by criterion EO1 'To attend the women who are assigned to them, in a welcoming manner, according to institutional protocol and with immediate access to the obstetrician when necessary' $(13,37 \%)$ - which contributed $57.38 \%$ to the 'Attendance' dimension index $(23.30 \%)$. Both criteria are of the professional category Obstetric Nurses, which had the criteria with the highest relative importance (preference decision) related to the safety of the maternal-child patient (46.47\%).

Based on the dimensions, the professional category Obstetric Nurses stood out in the three dimensions with the highest decision-making preferences: 'Integration' (22.74\%), 'Attendance' (13.37\%) and 'Administrative Aspects'). It was considered by the decision makers $(87.83 \%)$ the most preferred professional category among the criteria of the 'Team 
Decision-making preferences - By Criterion and Professional Category - of the Nursing Coordinators (CE).

$\begin{array}{llllllllll}\text { Criteria } & \text { CE1 CE2 CE3 CE4 CE5 CE6 CE7 CE8 Means Standard } & \text { Deviation }\end{array}$

\begin{tabular}{|c|c|c|c|c|c|c|c|c|c|c|c|}
\hline TAE & Technical / Nursing Assistant & 19.85 & 19.97 & 22.11 & 30.62 & 22.30 & 32.75 & 24.02 & 24.02 & 24.46 & 4.76 \\
\hline TAE1 & $\begin{array}{l}\text { Accept the woman and companion in a cordial and } \\
\text { responsible manner. }\end{array}$ & 50.47 & 8.35 & 2.88 & 3.52 & 6.26 & 6.63 & 8.08 & 6.33 & 11.57 & 15.84 \\
\hline TAE2 & $\begin{array}{l}\text { Listen to the woman's complaint, fears and } \\
\text { expectations. }\end{array}$ & 4.62 & 9.47 & 7.07 & 8.93 & 12.08 & 7.25 & 9.13 & 10.09 & 8.58 & 2.25 \\
\hline TAE3 & $\begin{array}{l}\text { Accommodate and / or position the user } \\
\text { appropriately so that it can be assessed in the risk } \\
\text { classification. }\end{array}$ & 2.50 & 7.44 & 3.25 & 8.32 & 8.68 & 14.62 & 9.28 & 11.97 & 8.26 & 4.04 \\
\hline TAE4 & Gauge the woman's vital signs. & 11.51 & 17.98 & 22.92 & 21.67 & 11.07 & 15.79 & 12.22 & 12.98 & 15.77 & 4.65 \\
\hline TAE5 & Refer the client for care after risk classification. & 3.36 & 9.39 & 2.88 & 12.71 & 8.57 & 9.69 & 9.83 & 12.21 & 8.58 & 3.65 \\
\hline TAE6 & $\begin{array}{l}\text { Forward / orient user regarding the location of the } \\
\text { examination and medication, when applicable. }\end{array}$ & 5.94 & 10.70 & 3.25 & 12.15 & 9.26 & 8.97 & 12.24 & 12.78 & 9.41 & 3.35 \\
\hline TAE7 & $\begin{array}{l}\text { Be alert to the woman's reclassification needs while } \\
\text { awaiting care. }\end{array}$ & 6.50 & 12.70 & 37.34 & 16.23 & 17.50 & 11.08 & 12.71 & 13.52 & 15.95 & 9.26 \\
\hline TAE8 & $\begin{array}{l}\text { Refer users to Social Work and Psychology when } \\
\text { appropriate. }\end{array}$ & 7.93 & 7.78 & 3.25 & 8.05 & 9.08 & 7.75 & 8.08 & 11.04 & 7.87 & 2.17 \\
\hline TAE9 & $\begin{array}{l}\text { Making the shift on a regular basis is not allowed } \\
\text { to leave the shift without another employee taking } \\
\text { it. }\end{array}$ & 7.19 & 16.19 & 17.16 & 8.43 & 17.50 & 18.21 & 18.42 & 9.09 & 14.02 & 4.87 \\
\hline $\mathrm{E}$ & Nurses & 34.69 & 37.59 & 31.89 & 25.82 & 34.64 & 25.99 & 20.98 & 20.98 & 29.07 & 6.48 \\
\hline E1 & $\begin{array}{l}\text { Receive the information sheets, evaluating the } \\
\text { women's priority in an agile and responsible } \\
\text { manner, according to the complaint presented. }\end{array}$ & 6.48 & 7.59 & 10.54 & 7.41 & 6.77 & 10.44 & 7.87 & 6.71 & 7.98 & 1.62 \\
\hline E2 & $\begin{array}{l}\text { Call the woman by name, also requesting the } \\
\text { presence of a companion. }\end{array}$ & 7.77 & 6.88 & 5.69 & 7.59 & 9.69 & 14.52 & 7.31 & 7.72 & 8.40 & 2.71 \\
\hline E3 & $\begin{array}{l}\text { Classify the risk quickly and efficiently, following } \\
\text { the protocol adopted. }\end{array}$ & 11.00 & 8.58 & 9.85 & 9.44 & 8.58 & 11.36 & 9.66 & 16.05 & 10.57 & 2.43 \\
\hline E4 & $\begin{array}{l}\text { Attach the "notice of violence" form when there is } \\
\text { suspicion or confirmation of the case. }\end{array}$ & 5.95 & 7.68 & 4.47 & 10.19 & 7.42 & 8.71 & 9.24 & 4.54 & 7.28 & 2.13 \\
\hline E5 & $\begin{array}{l}\text { Record classification data in the answer sheet, } \\
\text { signaling the woman's classification by color. }\end{array}$ & 12.85 & 9.12 & 7.31 & 11.04 & 6.75 & 9.21 & 9.94 & 11.29 & 9.69 & 2.05 \\
\hline E6 & Record rankings on the $A$ \& CR map. & 6.86 & 6.44 & 5.07 & 5.03 & 6.35 & 3.86 & 5.57 & 3.78 & 5.37 & 1.16 \\
\hline E7 & $\begin{array}{l}\text { Orient the woman in a clear way about her } \\
\text { situation and the waiting time of the service. }\end{array}$ & 7.86 & 7.36 & 6.23 & 10.78 & 8.58 & 5.26 & 7.08 & 10.40 & 7.94 & 1.92 \\
\hline E8 & $\begin{array}{l}\text { Provide the technician's answer sheet to be placed } \\
\text { in the offices. }\end{array}$ & 4.69 & 7.14 & 1.98 & 5.33 & 6.43 & 4.92 & 6.08 & 5.46 & 5.25 & 1.55 \\
\hline E9 & Reclassify users when necessary. & 8.67 & 12.16 & 19.15 & 11.77 & 14.86 & 9.24 & 9.75 & 13.82 & 12.43 & 3.48 \\
\hline E10 & $\begin{array}{l}\text { Be integrated with the multiprofessional team of } \\
\text { the obstetrical / maternity center, seeking a better } \\
\text { solution to the problems of the user. }\end{array}$ & 11.34 & 10.44 & 14.70 & 9.29 & 9.61 & 9.49 & 12.34 & 9.05 & 10.78 & 1.94 \\
\hline
\end{tabular}


Decision-making preferences - By Criterion and Professional Category - of the Nursing Coordinators (CE).

\begin{tabular}{|c|c|c|c|c|c|c|c|c|c|c|c|}
\hline & Criteria & CE1 & CE2 & CE3 & CE4 & CE5 & CE6 & CE7 & CE8 & Means & Standard \\
\hline E11 & $\begin{array}{l}\text { Supervise the work of the technician / nursing } \\
\text { assistant and trainee, guiding correctly when } \\
\text { necessary. }\end{array}$ & 12.16 & 10.71 & 10.80 & 6.81 & 8.98 & 9.10 & 10.85 & 7.04 & 9.56 & 1.92 \\
\hline E12 & $\begin{array}{l}\text { Record the occurrences of the sector in the proper } \\
\text { book. }\end{array}$ & 4.35 & 5.91 & 4.22 & 5.33 & 5.96 & 3.90 & 4.30 & 4.15 & 4.77 & 0.83 \\
\hline EO & Obstetric Nurses & 45.46 & 42.44 & 46.00 & 43.56 & 43.06 & 41.26 & 55.00 & 55.00 & 46.47 & 5.48 \\
\hline E01 & $\begin{array}{l}\text { To attend the women who are assigned to them, in } \\
\text { a welcoming way, according to institutional } \\
\text { protocol and with the immediate access to the } \\
\text { obstetrician, when necessary. }\end{array}$ & 43.15 & 22.31 & 29.50 & 24.33 & 28.74 & 24.22 & 20.19 & 36.80 & 28.66 & 7.81 \\
\hline EO2 & $\begin{array}{l}\text { Communicate the nursing team about the adopted } \\
\text { behavior: admission, observation, reassessment or } \\
\text { discharge of the woman. }\end{array}$ & 18.44 & 21.10 & 12.94 & 32.03 & 20.47 & 17.59 & 25.89 & 21.25 & 21.21 & 5.72 \\
\hline EO3 & $\begin{array}{l}\text { Be integrated with the multiprofessional team of } \\
\text { the obstetrical / maternity center, seeking a better } \\
\text { solution to the women's problems. }\end{array}$ & 21.58 & 31.65 & 41.72 & 26.93 & 24.82 & 22.91 & 23.63 & 27.96 & 27.65 & 6.53 \\
\hline EO4 & $\begin{array}{l}\text { Make the shift on a regular basis, not leaving it } \\
\text { without another employee taking it. }\end{array}$ & 16.83 & 24.94 & 15.85 & 16.71 & 25.97 & 35.28 & 30.29 & 13.98 & 22.48 & 7.79 \\
\hline
\end{tabular}

Source: Elaborated by the authors of the research with the help of Software D-Sight, 2016.

Table 3

Decision preferences - By Dimension, Criterion and Professional Category - of the Nursing Coordinators (CE).

\begin{tabular}{|c|c|c|c|c|c|c|c|c|c|c|c|c|}
\hline Dimensions & & Criteria & CE1 & CE2 & CE3 & CE4 & CE5 & CE6 & CE7 & CE8 & Means & $\begin{array}{l}\text { Standard } \\
\text { Deviation }\end{array}$ \\
\hline \multirow[t]{4}{*}{$\begin{array}{c}\text { Reception } \\
9,21 \%\end{array}$} & TA1 & $\begin{array}{l}\text { Accept the woman and } \\
\text { companion in a cordial and } \\
\text { responsible manner. }\end{array}$ & 10.02 & 1.67 & 0.64 & 1.08 & 1.40 & 2.17 & 1.94 & 1.52 & 2.55 & 3.05 \\
\hline & TA2 & $\begin{array}{l}\text { Listen to the woman's complaint, } \\
\text { fears and expectations. }\end{array}$ & 0.92 & 1.89 & 1.56 & 2.73 & 2.69 & 2.37 & 2.19 & 2.42 & 2.10 & 0.62 \\
\hline & TA3 & $\begin{array}{l}\text { Accommodate and / or position } \\
\text { the user appropriately so that it } \\
\text { can be assessed in the risk } \\
\text { classification. }\end{array}$ & 0.50 & 1.49 & 0.72 & 2.55 & 1.94 & 4.79 & 2.23 & 2.88 & 2.14 & 1.36 \\
\hline & E2 & $\begin{array}{l}\text { Call the woman by name, also } \\
\text { requesting the presence of a } \\
\text { companion. }\end{array}$ & 2.70 & 2.59 & 1.81 & 1.96 & 3.36 & 3.77 & 1.53 & 1.62 & 2.42 & 0.83 \\
\hline \multirow[t]{2}{*}{$\begin{array}{c}\text { Classification } \\
14,90 \%\end{array}$} & TA7 & $\begin{array}{l}\text { Be alert to the woman's } \\
\text { reclassification needs while } \\
\text { awaiting care. }\end{array}$ & 1.29 & 2.54 & 8.25 & 4.97 & 3.90 & 3.63 & 3.05 & 3.25 & 3.86 & 2.07 \\
\hline & E3 & $\begin{array}{l}\text { Classify the risk quickly and } \\
\text { efficiently, following the } \\
\text { protocol adopted. }\end{array}$ & 3.82 & 3.23 & 3.14 & 2.44 & 2.97 & 2.95 & 2.03 & 3.37 & 2.99 & 0.55 \\
\hline
\end{tabular}

Source: Elaborated by the authors of the research with the help of Software D-Sight, 2016. 
Decision preferences - By Dimension, Criterion and Professional Category - of the Nursing Coordinators (CE).

\begin{tabular}{|c|c|c|c|c|c|c|c|c|c|c|c|c|}
\hline Dimensions & & Criteria & CE1 & CE2 & CE3 & CE4 & CE5 & CE6 & CE7 & CE8 & Means & $\begin{array}{l}\text { Standard } \\
\text { Deviation }\end{array}$ \\
\hline \multirow[t]{3}{*}{$\begin{array}{c}\text { Classification } \\
14,90 \%\end{array}$} & E5 & $\begin{array}{l}\text { Record classification data in the } \\
\text { answer sheet, signaling the } \\
\text { woman's classification by color. }\end{array}$ & 4.46 & 3.43 & 2.33 & 2.85 & 2.34 & 2.39 & 2.09 & 2.37 & 2.78 & 0.80 \\
\hline & E6 & $\begin{array}{l}\text { Record rankings on the } A \& C R \\
\text { map. }\end{array}$ & 2.38 & 2.42 & 1.62 & 1.30 & 2.20 & 1.00 & 1.17 & 0.79 & 1.61 & 0.65 \\
\hline & E9 & Reclassify users when necessary. & 3.01 & 4.57 & 6.11 & 3.04 & 5.15 & 2.40 & 2.05 & 2.90 & 3.65 & 1.44 \\
\hline Attendance & TA4 & Gauge the woman's vital signs. & 2.28 & 3.59 & 5.07 & 6.63 & 2.47 & 5.17 & 2.94 & 3.12 & 3.91 & 1.55 \\
\hline \multirow[t]{4}{*}{$23,30 \%$} & TA5 & $\begin{array}{l}\text { Refer the client for care after risk } \\
\text { classification. }\end{array}$ & 0.67 & 1.88 & 0.64 & 3.89 & 1.91 & 3.17 & 2.36 & 2.93 & 2.18 & 1.16 \\
\hline & E1 & $\begin{array}{l}\text { Receive the information sheets, } \\
\text { evaluating the women's priority } \\
\text { in an agile and responsible } \\
\text { manner, according to the } \\
\text { complaint presented. }\end{array}$ & 2.25 & 2.85 & 3.36 & 1.91 & 2.35 & 2.71 & 1.65 & 1.41 & 2.31 & 0.65 \\
\hline & E8 & $\begin{array}{l}\text { Provide the technician's answer } \\
\text { sheet to be placed in the offices. }\end{array}$ & 1.63 & 2.68 & 0.63 & 1.38 & 2.23 & 1.28 & 1.28 & 1.15 & 1.53 & 0.65 \\
\hline & EO1 & $\begin{array}{l}\text { To attend the women who } \\
\text { compete with them, in a } \\
\text { welcoming way, according to } \\
\text { institutional protocol and with } \\
\text { the immediate access to the } \\
\text { obstetrician, when necessary. }\end{array}$ & 19.62 & 9.47 & 13.57 & 10.60 & 12.38 & 9.99 & 11.10 & 20.24 & 13.37 & 4.25 \\
\hline \multirow[t]{2}{*}{$\begin{array}{l}\text { Orientation } \\
4,63 \%\end{array}$} & TA6 & $\begin{array}{l}\text { Forward / orient user regarding } \\
\text { the location of the examination } \\
\text { and medication, when } \\
\text { applicable. }\end{array}$ & 1.18 & 2.14 & 0.72 & 3.72 & 2.06 & 2.94 & 2.94 & 3.07 & 2.35 & 1.02 \\
\hline & E7 & $\begin{array}{l}\text { Orient the woman in a clear way } \\
\text { about her situation and the } \\
\text { waiting time of the service. }\end{array}$ & 2.73 & 2.77 & 1.99 & 2.78 & 2.97 & 1.37 & 1.49 & 2.18 & 2.28 & 0.62 \\
\hline \multirow[t]{3}{*}{$\begin{array}{c}\text { Team } \\
\text { Integration } \\
25,89 \%\end{array}$} & E10 & $\begin{array}{l}\text { Be integrated with the } \\
\text { multiprofessional team of the } \\
\text { obstetrical / maternity center, } \\
\text { seeking a better solution to the } \\
\text { problems of the user. }\end{array}$ & 3.93 & 3.92 & 4.69 & 2.40 & 3.33 & 2.47 & 2.59 & 1.90 & 3.15 & 0.97 \\
\hline & EO2 & $\begin{array}{l}\text { Communicate the nursing team } \\
\text { about the adopted behavior: } \\
\text { admission, observation, } \\
\text { reassessment or discharge of the } \\
\text { woman. }\end{array}$ & 8.38 & 8.95 & 5.95 & 13.95 & 8.81 & 7.26 & 14.24 & 11.69 & 9.91 & 3.06 \\
\hline & EO3 & $\begin{array}{l}\text { Be integrated with the } \\
\text { multiprofessional team of the } \\
\text { obstetrical / maternity center, } \\
\text { seeking a better solution to the } \\
\text { women's problems. }\end{array}$ & 9.81 & 13.43 & 19.19 & 11.73 & 10.69 & 9.45 & 13.00 & 15.38 & 12.83 & 3.24 \\
\hline
\end{tabular}

continue

Source: Elaborated by the authors of the research with the help of Software D-Sight, 2016. 
Decision preferences - By Dimension, Criterion and Professional Category - of the Nursing Coordinators (CE).

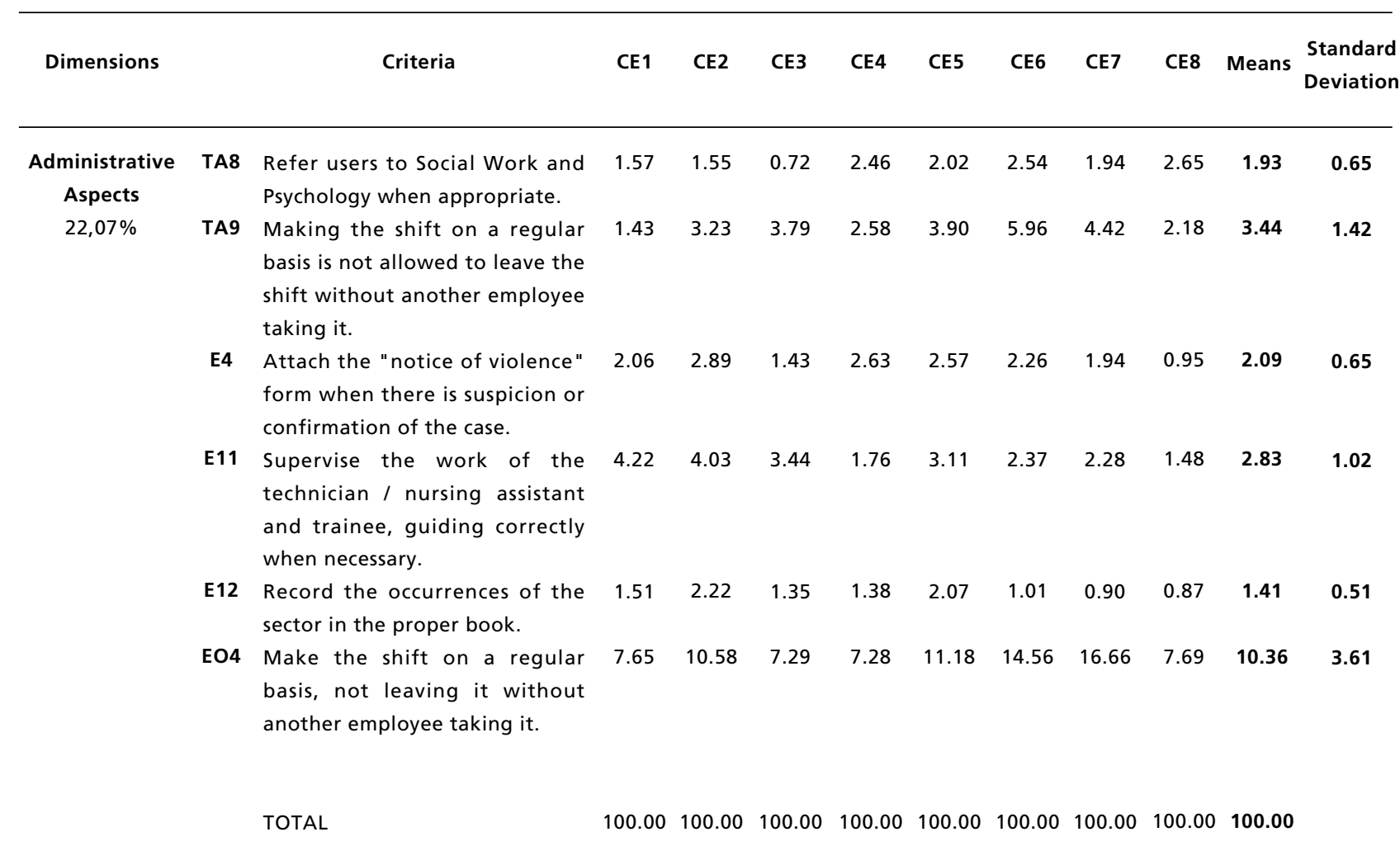

Source: Elaborated by the authors of the research with the help of Software D-Sight, 2016.

Integration' dimension (25.89\%). In the following two dimensions, the Nurses category (74.09\%) was the one that presented the highest preference among the criteria of the 'Classification' dimension (14.90\%); and the Nurse Technicians and Assistants $(73.72 \%)$, who presented the highest preference among the criteria of the 'Reception' dimension $(9.21 \%)$. In the 'Orientation' dimension $(4.63 \%)$, their criteria were those with the lowest preference, with a balance of preferences between the categories of Nurse Technicians and Assistants (2.35\%) and Nurses (2.28\%).

Based on the professional categories, a greater preference of the decision-makers was observed according to the criteria of the professional category Obstetric Nurses $(46.47 \%)$, which presented an index higher than $50 \%$ for each of the other two categories: Nurses $(29.07 \%)$ and Nurse Technicians and Assistants (24.46\%).

The sensitivity analysis was applied in all professional categories to verify the robustness of the model. This analysis was verified at the end of the answers of each decision maker through D-Sight Software, which did not diagnose inconsistencies during the graphic capture of preferences. In the graphical stability analysis, all points generated by the Software were within acceptable limits (Figure 1). Stability intervals indicate the limits by which there may be a change in the weighting of the criteria without there being a change in the hierarchy and indicates consistency in the total results.

\section{Discussion}

The Multicriteria Decision Analysis (MCDA) is applied to a wide range of areas in health care, through the use of a variety of methodological approaches. A systematic review conducted in 2015 between English-language studies from 1980 to 2013 found an increased use of MCDA in health care. Most of the studies were published in the United States, and medical decision making was the 
predominant issue among all studies, with cancer being the most researched disease and the most comprehensive diagnosis and treatment. 19

Multicriteria methods help people make better choices when faced with complex decisions involving multiple dimensions, especially in patientcentered decisions that are by nature multidimensional and involve multiple decision makers. Decisions of this kind incorporate personal preferences, values and circumstances unique to the decision-making process and actively involve both patients and health care providers. ${ }^{20}$

It is also worth noting that the criteria of dimensions not directly involved with the patient - 'Team Integration' and 'Administrative Aspects' - had a high decision-making preference $(47.96 \%)$ for maternal and child safety. This illustrates the need to prioritize decision-making for the planning of nursing care management, considering the impact it brings to patient safety and quality of nursing care. 21

Team integration has been extensively discussed in studies that focus on patient safety. The abscence, together with the lack of communication between the units, greatly weakens teamwork in hospital units. 22 The debate about the need to integrate safety culture into nursing practice, through educational strategies that contribute to the quality of care provided and that prevent adverse events through hospital risk management tends to grow. ${ }^{23}$ In this context, the inclusion and active participation of nursing professionals in a shared management environment for the implementation of the safety culture is suggested, 21 because the processes of decision-making when not shared hinder co-responsibility and lead to a centrality in the decision of nursing behaviors. 24

With a common vision and direction for organizational goals, teamwork in the configuration of health care is an ongoing process of interaction, coordinated cooperatively, and with shared communication focused on caring for all patients. 25 It is understood as collaborative interprofessional practice, involving an articulated team with collaboration between professionals from different areas and patient-centered.24-26

The nursing profession is the most cited in studies on collaborative interprofessional practice and interprofessional education. ${ }^{27}$ However, contradicting these citations, several studies show the inexistence of interaction and effective articulation of their actions in technical procedures. This leads to a technical division of labor, characterizing as a collective work organization, what differentiates it from a teamwork that is integrated and collaborative. $24,28,29$
Recent safety and error prevention publications have considered the breakdown in communication or the lack of teamwork one of the factors that most contribute to adverse health care events. Damage to the patient, increased length of hospital stay and inefficient use of resources are some of the results of this communication breakdown. 25

The change in shift seen in the criteria TA9 and EO4 criteria of this study totaled $13.8 \%$ of the decision preferences for patient safety, representing $62.53 \%$ of the 'Administrative Aspects' dimension $(22.07 \%)$, the third dimension most preferred. However, some publications have shown little importance to these aspects, where no systematized routine for the transfer of information and / or documents between the different sectors that provide care to the patient existed.22

The standard deviation values in the study signaled that each decision maker constructed his/her decision context differently, regardless of optimal decision-making indicators, but rather as an alignment of the numerical results that pointed to recommendations for decision support. 16 They allow decision makers to be able to orient their decisions towards criteria that are in the higher preference rankings, pointing to a less fragile decision regarding the safety of the maternal and child patient.

Investments aimed at managing people and encouraging effective communication and teamwork provide a better interpersonal relationship, integrate the team and, consequently, promote a patient's safety culture. 21 The effective work of the team by means of practice and collaborative interprofessional education,27 with an emphasis on leadership, communication and the clear definition of roles, 25 coupled with effective management and priority for shift changes ${ }^{21}$ and a friendly care based on institutional protocols and a correct classification were found to be important and which support the decision.

Despite the need to develop practical guidelines for the proper application of MCDA methods, ${ }^{19}$ they are especially useful when they are able to combine 'hard data' - criteria - with subjective preferences. Thus, compromises are created between the desired results (patient safety) involving multiple decision makers - nursing coordinators, technicians and auxiliaries, nurses and obstetric nurses. ${ }^{20}$

The result of the interaction between the various criteria, the ranking of MCDA-C decision preferences through PROMETHEE and their weighting with dimensions, enabled a clear and coherent decision model, which signaled the most important nursing assignments relative to the patient's safety. 
The authors consider that the study may present limitations related to the difficulties of understanding the use of the MCDA methodology, due to its complexity, requiring the reader to consult complementary material. Another aspect is the need to apply decision preferences in a geographical area different from the locality of the research, considering the possibility of variations in the subjective aspects and values of decision makers from other localities. However, despite its limitations, the deci- sion-making preference model provided innovative contributions in prioritizing actions and investments to provide greater maternal and child patient safety.

\section{Acknowledgements}

The present study was funded by the Foundation for Science and Technology Support of the State of Pernambuco (FACEPE).

\section{References}

1. Martins M, Travassos C, Mendes W, Pavão ALB. Hospita deaths and adverse events in Brazil. BMC Health Serv Res. 2011; $11: 223$.

2. Sousa P, Uva AS, Serranheira F, Nunes C, Leite ES Estimating the incidence of adverse events in Portuguese hospitals: a contribution to improving quality and patient safety. BMC Health Serv Res. 2014; 14: 311.

3. Amaya SL. Seguridad del Paciente: Conceptos e análisis de eventos adversos. Centro de Gestión Hospitalaria/ ViaSALUD. 2009; (48): 6-21

4. Mendes W, Travassos C, Martins M, Marques PM Adaptação dos instrumentos de avaliação de eventos adversos para uso em hospitais brasileiros. Rev bras epidemio. 2008; 11(1): 55-66.

5. Nascimento CCP, Toffoletto MC, Gonçalves LA, Freitas WG, Padilha KG. Indicadores de resultados da assistência: análise dos eventos adversos durante a internação hospitalar. Rev Latino-Am Enfermagem. 2008; 16 (4): 746-51.

6. Leape LL, Brennan TA, Laird N, Lawthers AG, Localio AR, Barnes BA, Hebert L, Newhouse JP, Weiler PC, Hiatt H. The Nature of Adverse Events in Hospitalized Patients: Results of the Harvard Medical Practice Study II. N Engl J Med. 1991; 324: 377-84.

7. Vicent C, Taylor-Adams S, Stanhope N. Framework for analysing risk and safety in clinical medicine. BMJ. 1998; 316 (7138): 1154-7.

8. Vicent C. Understanding and Responding to Adverse Events. N Engl J Med. 2003; 348(11): 1051-6.

9. Sommella L, Waure C, Ferriero AM, Biasco A, Mainelli MT, Pinnarelli L, Ricciardi W, Damiani G. The incidence of adverse events in an Italian acute care hospital: findings of a two-stage method in a retrospective cohort study. BMC Health Serv Res. 2014; 14(1): 358.

10. Brasil. Ministério da Saúde. Agência Nacional de Vigilância Sanitária. Resolução de Diretoria Colegiada RDC Nº36, 25 de julho de 2013. Institui ações para a segurança do paciente em serviços de saúde e dá outras providências. Disponível em: http://portal.anvisa.gov.br/ documents/10181/2871504/RDC_36_2013 COMP.pdf/36d 809a4-e5ed-4835-a375-3b3e93d74d5e

11. Pedroso M. Inteligência decisória e análise de políticas públicas: o caso das Unidades de Pronto Atendimento (UPAs) [tese]. Brasília: Faculdade de Economia, Administração e Contabilidade da Universidade de Brasília; 2011
12. March JG. Como as Decisões Realmente Acontecem: Princípios da Tomada de Decisões São Paulo: Leopardo Editora; 2010.

13. Simon HA. The Sciences of the Artificial. 3 ed. Massachusetts: Massachusetts Institute of Technology; 1996

14. Mareschal B, De Smet Y. Visual PROMETHEE: Developments of the PROMETHEE \& GAIA Multicriteria Decision Aid Methods. IEEE. 2009; 1646-1649.

15. Bana e Costa CA. Três convicções fundamentais na prática do apoio à decisão. In Pesquisa Operacional.: Sociedade Brasileira de Pesquisa Operacional; 1993.9-20.

16. Ensslin L, Montibeller Neto G, Noronha SM. Apoio à Decisão: Metodologias para Estruturação de Problemas e Avaliação Multicritério de Alternativas. 1 ed. Moura NRd, editor. Florianópolis: Insular; 2001.

17. Brasil. Ministério da Saúde. Iniciativa hospital amigo da criança. 2014. [acesso em 31 mar 2016]. Disponível em: http://portalms.saude.gov.br/saude-para-voce/saude-dacrianca/pre-natal-e-parto/iniciativa-hospital-amigo-dacrianca-ihac

18. Brasil. Ministério da Saúde. Rede Cegonha/DAPES/SAS. Manual de Acolhimento e Classificação de Risco em Obstetrícia; 2014

19. Adunlin G, Diaby V, Xiao H. Application of multicriteria decision analysis in health care: a systematic review and bibliometric analysis. Health Expect. 2015; 18(6):1894905 .

20. Dolan JG. Multi-criteria clinical decision support: A primer on the use of multiple criteria decision making methods to promote evidence-based, patient-centered healthcare. Patient. 2010; 3(4): 229-48.

21. Oliveira RM, Leitão IMTdA, Silva LMS, Figueiredo SV, Sampaio RL, Gondim MM. Estratégias para promover segurança do paciente: da identificação dos riscos às práticas baseadas em evidências. Esc Anna Nery. 2014; 18(1): 122-9.

22. Tobias GC, Bezerra ALQ, Moreira IA, Paranaguá TTdB, Silva AEBdC. Conhecimento dos enfermeiros sobre a cultura de segurança do paciente em hospital universitário. Rev enferm UFPE on line. 2016; 10(3): 1071-9.

23. Silva RFA, Filho RDB, Santos M, Nascimento MAL. Estratégia educacional como contribuinte ao gerenciamento de risco hospitalar: estudo quase-experimental. Online Brazilian J Nurs. 2011; 10(1): 8. 
24. Souza GC, Peduzzi M, Silva JAM, Carvalho BG. Trabalho em equipe de enfermagem: circunscrito à profissão ou colaboração interprofissional? Rev Esc Enferm USP. 2016; 50(4): 642-9.

25. Oluborode O. Effective communication and teamwork in promoting patient safety. [Online]; 2013 [cited 2017 Agosto 6. Disponível em: http://sqhn.org/effective-communication-and-teamwork-in-promoting-patient-safety/

26. University of British Columbia. Canadian Interprofessional Health Collaborative (CIHC). Interprofessional education \& core competencies. Canada. 2010.

27. Brandt B, Lutfiyya MN, King JA, Chioreso C. A scoping review of interprofessional collaborative practice and education using the lens of Triple Aim. J Interprof Care. 2014; 28(5): 393-9.

Received on September 21, 2017

Final version presented on July 05, 2018

Approved on July 17, 2018
28. Baindridge L, Nasmith L, Orchard C, Wood V. Competencies for interprofessional collaboration. J Phys Ther Educ. 2010; 24(1): 6-11.

29. Lorenzetti J, Oro J, Matos E, Gelbcke FL. Organização do trabalho da enfermagem hospitalar: abordagens na literatura. Texto Contexto Enferm. 2014; 23(4): 1104-12.

30. D-SIGHT. Structured Approach to Project Prioritization \& Investment Capacity Planning. [Online].; 2016 [cited 2016 Agosto 15. Disponível em: http://www.d-sight.com . 